\title{
Antimicrobial Resistance and Biofilm Production Potential of Staphylococci from Bovine Mastitis in Andhra Pradesh
}

\author{
Bhavana, R.N., Chaitanya, R.K.", Vinod Kumar, N. and Sreedevi, B. \\ Department of Veterinary Microbiology, College of Veterinary Science, Sri Venkateswara Veterinary University, Tirupati, INDIA \\ *Corresponding author: RK Chaitanya; E-mail: chaitanyaerk@gmail.com
}

Received: 18 Jan., 2021

Revised: 03 March, 2021

Accepted: 09 March, 2021

\begin{abstract}
Bovine mastitis is a frequent cause of economic loss to dairy farmers. This study is aimed at investigating the biofilm formation ability and antimicrobial resistance of Staphylococci from bovine mastitis. Among a total of 125 Staphylococcal isolates obtained from cows and she buffaloes with clinical and subclinical mastitis, 45 were coagulase positive (CPS) and 80 were identified as coagulase negative (CoNS) by tube coagulase test. Considerably high proportion of Staphylococcal isolates (56/125, 45\%) formed biofilms on Congo red agar and when these isolates were screened for biofilm genes (icaA, bap, icaAB, aap), only four $(7.2 \%)$ were found to possess bap gene. The icaA, icaAB and aap genes were not detected in any of the isolates. Majority of the CPS and CoNS isolates from our study (around 96\%) were susceptible to ciprofloxacin and ceftriaxone, but most of them were resistant to gentamicin (100\% of CPS and $92.5 \%$ of CoNS). The isolates $(49 / 125,39.2 \%)$ that showed resistance to cefoxitin were phenotypically identified as methicillin resistant, out of which 10 were MRSA and 39 were CoNS. In PCR for $m e c A$ and $m e c C$ genes, only eight isolates $(8 / 125,6.4 \%)$ of Staphylococci were found to possess mecA gene. None of the isolates carried $m e c C$ gene. The results suggest that the CoNS isolates (44.8\%) from bovine mastitis had the potential to form biofilms and has considerably high (49\%) methicillin resistant phenotype though only 6.25 per cent of them carried mecA gene and could be confirmed as MRCoNS.
\end{abstract}

\section{HIGHLIGHTS}

(0) Only $6.4 \%$ of the Staphylococcal isolates possessed 'mecA' gene that confers methicillin resistance.

( $44.8 \%$ of the CoNS isolates showed biofilm production ability on Congo red agar.

(O Only in $7.2 \%$ of the Staphylococcal isolates 'bap' gene was detected.

Keywords: Bovine mastitis, CoNS, biofilm, methicillin resistance, mec A, bap.

Mastitis affects the health of dairy cows resulting in decreased milk production and quality. Staphylococci are the major cause of mastitis in different countries around the world. CoNS have traditionally been considered to be of minor pathogenicity, but in recent years their role as cause of bovine mastitis is increasingly evident. Infections with CoNS results in tissue damage, decrease in milk production and persistent intramammary infections, and CoNS have been isolated from milk samples collected from cows with clinical and subclinical mastitis in several countries (Srednik et al., 2015). Virulence of S. aureus and CoNS in mastitis and other infections is attributed to biofilm formation, which confers resistance to antibiotics and offers protection against hostile environments. Biofilm production is dependent on the presence of genes such as $i c a A$, icaB, icaAB, icaC, icaD, bap, aap, fbe, embp and atlE that code for biofilm-associated proteins and extracellular polysaccharide substances (Tremblay et

How to cite this article: Bhavana, R.N., Chaitanya, R.K., Vinod Kumar, N and Sreedevi, B. (2021). Antimicrobial Resistance and Biofilm Production Potential of Staphylococci from Bovine Mastitis in Andhra Pradesh. J. Anim. Res., 11(2): 299-304.

Source of Support: None; Conflict of Interest: None 
al., 2013). The intracellular adhesion locus 'ica $A B C D$ ' encodes the proteins responsible for the synthesis of poly-N-acetyl glucosamine (PNAG), 'bap' gene encodes the biofilm-associated protein, and 'aap' the accumulation-associated protein. Several antibiotic resistance mechanisms have been described among CoNS strains from bovine mastitis, including $\beta$-lactamase production encoded by blaZ gene and production of low-affinity penicillin-binding proteins (PBP2a) encoded by mecA or mecC. The mecA gene confers methicillin resistance. Currently, $\beta$-lactam antimicrobials, aminoglycosides, and macrolides are commonly used to treat mastitis. Resistance to these antibiotics has been increasingly reported in CoNS associated with bovine mastitis. This study involves antimicrobial susceptibility testing, screening for biofilm production of the Staphylococcal isolates from bovine mastitis and detection of resistance and biofilm genes.

\section{MATERIALS AND METHODS}

\section{Collection of samples}

A total of 237 milk samples were collected from cows and she buffaloes with different parity, age and postpartum period affected with mastitis, randomly from different regions of Andhra Pradesh during the period from April 2019 to September 2019. Milk samples were streaked on Mannitol salt agar (MSA) and Mac Conkey agar (MAC) plates and incubated at $37^{\circ} \mathrm{C}$ for about $48 \mathrm{hr}$. Single colonies were identified based on Gram's staining, colony morphology and catalase test. The Staphylococcus species were further differentiated by tube coagulase test.

\section{Genomic DNA extraction}

Genomic DNA was isolated using lysis method (boiling method). Three ml of overnight broth culture was taken and cells were pelleted by centrifugation at $10000 \mathrm{rpm}$ for $10 \mathrm{~min}$. The pellet was washed with PBS by centrifugation at $10000 \mathrm{rpm}$ for $10 \mathrm{~min}$. The pellet was resuspended in $200 \mu \mathrm{l}$ of TE buffer by gentle mixing and boiled at $95{ }^{\circ} \mathrm{C}$ for $20 \mathrm{~min}$. This was followed by snap chilling at $-20{ }^{\circ} \mathrm{C}$ for $10 \mathrm{~min}$.
The suspension was centrifuged at $10000 \mathrm{rpm}$ for 10 min and the resultant supernatant containing DNA was stored at $-20^{\circ} \mathrm{C}$ for use in PCR protocols.

\section{Screening for biofilm production ability}

All the Staphylococcal isolates were checked for their ability to produce biofilm using modified Congo red agar (Mariana et al., 2009). Congo Red Agar plates were inoculated with the Staphylococcal isolates and incubated at $37^{\circ} \mathrm{C}$ for $48 \mathrm{hr}$ initially and subsequently at room temperature for 2-4 days. The slime producing strains form strong black pigmentation to slightly black colonies, which indicates positive for biofilm production, where as non-slime producers develop red colonies which indicates negative for biofilm production.

\section{Detection of biofilm genes by PCR}

The Staphylococcal isolates that were found to form biofilm on Congo Red agar were screened for the presence of biofilm genes viz., icaA, bap, icaAB and aap, which are majorly associated with the biofilm production. The oligonucleotide primers, PCR cycle conditions and the corresponding amplicon sizes for the biofilm genes were mentioned in Table 1.

First the isolates were screened for icaA and bap genes in duplex PCR as per the method of Janeczko et al. (2014). Further, the Staphylococcal isolates that showed positive biofilm phenotype were also screened for the presence of icaAB gene (Iorio et al., 2011) and aap gene (Srednik et al., 2017) in two separate PCR tests.

\section{Phenotypic characterization of antibiotic resistance}

For all the Staphylococcal isolates, antimicrobial susceptibility test was performed by the standard Kirby Bauer disc diffusion method on Muller Hinton agar according to Clinical and Laboratory Standards Institute (CLSI) guidelines (CLSI, 2014). The isolates were tested for susceptibility to the following antibiotics viz., cefoxitin (CX30), ceftriaxone (CTR30), ciprofloxacin (CIP5), gentamicin (GEN10), oxacillin (OX1) and penicillin $\mathrm{G}$ (P10). CoNS isolates 
Table 1: Oligonucleotide primer sequences for PCR

\begin{tabular}{|c|c|c|c|}
\hline $\begin{array}{l}\text { Target } \\
\text { Gene }\end{array}$ & Primer sequence 5'-3' & $\begin{array}{l}\text { Amplicon } \\
\text { size (bp) }\end{array}$ & Reference \& PCR conditions \\
\hline \multirow{2}{*}{$i c a A$} & icaA-F TCTCTTGCAGGAGCAATCAA & \multirow{2}{*}{188} & Janeczko et al. (2014) \\
\hline & icaA-R TCAGGCACTAACATCCAGCA & & \multirow{3}{*}{$\begin{array}{l}95^{\circ} \mathrm{C} \text { for } 3 \mathrm{~min}, 35 \text { cycles of } 95^{\circ} \mathrm{C} \text { for } 30 \\
\mathrm{sec}, 52{ }^{\circ} \mathrm{C} \text { for } 30 \mathrm{sec}, 72^{\circ} \mathrm{C} \text { for } 1 \mathrm{~min} \text { and } \\
\text { finally } 72^{\circ} \mathrm{C} \text { for } 5 \mathrm{~min} .\end{array}$} \\
\hline \multirow{2}{*}{ Bap } & bap-F CCCTATATCGAAGGTGTAGAATTGCAC & \multirow{2}{*}{971} & \\
\hline & bap-R GCTGTTGAAGTTAATACTGTACCTGC & & \\
\hline \multirow[b]{2}{*}{$i c a A B$} & icaAB-F TTATCAATGCCGCAGTTGTC & \multirow[b]{2}{*}{546} & Iorio et al. (2011) \\
\hline & icaAB-R GTTTAACGCGAGTGCGCTAT & & $\begin{array}{l}94{ }^{\circ} \mathrm{C} \text { for } 3 \mathrm{~min}, 30 \text { cycles of } 94^{\circ} \mathrm{C} \text { for } 1 \\
\text { min, } 58^{\circ} \mathrm{C} \text { for } 1 \mathrm{~min}, 72^{\circ} \mathrm{C} \text { for } 1 \mathrm{~min} \text { and } \\
\text { finally } 72^{\circ} \mathrm{C} \text { for } 5 \mathrm{~min} .\end{array}$ \\
\hline \multirow{3}{*}{ Aap } & aаp-F GAAGCACCGAATGTTCCAАСТАTC & \multirow{3}{*}{289} & Srednik et al. (2017) \\
\hline & & & $94^{\circ} \mathrm{C}$ for 6 min, 30 cycles of $94^{\circ} \mathrm{C}$ for 30 \\
\hline & aap-R AGTTGGCGGTATATCTATTGTA & & $\begin{array}{l}\mathrm{sec}, 52^{\circ} \mathrm{C} \text { for } 30 \mathrm{sec}, 72{ }^{\circ} \mathrm{C} \text { for } 30 \mathrm{sec} \text { and } \\
\text { finally } 72^{\circ} \mathrm{C} \text { for } 10 \mathrm{~min} .\end{array}$ \\
\hline \multirow{3}{*}{ mecA } & & \multirow{3}{*}{310} & Vishnu Priya et al. (2014) \\
\hline & $m e c A$-F GTAGAAATGACTGAACGTCCGATAA & & $94^{\circ} \mathrm{C}$ for $5 \mathrm{~min}, 30$ cycles of $94^{\circ} \mathrm{C}$ for 45 \\
\hline & $m e c A$-R CCAATTCCACATTGTTTCGGTCTAA & & $\begin{array}{l}\text { finally } 72{ }^{\circ} \mathrm{C} \text { for } 10 \mathrm{~min} \text {. } \\
\text { foc }\end{array}$ \\
\hline \multirow[b]{2}{*}{ mecC } & $m e c C$-F CATTAAAATCAGAGCGAGGC & \multirow[b]{2}{*}{188} & Paterson et al. (2012) \\
\hline & mecC-R TGGCTGAACCCATTTTTGAT & & $\begin{array}{l}94^{\circ} \mathrm{C} \text { for } 5 \mathrm{~min}, 36 \text { cycles of } 94^{\circ} \mathrm{C} \text { for } \\
30 \mathrm{sec}, 55^{\circ} \mathrm{C} \text { for } 30 \mathrm{sec}, 72^{\circ} \mathrm{C} \text { for } 30 \mathrm{sec} \text {, } \\
\text { finally } 72^{\circ} \mathrm{C} \text { for } 5 \mathrm{~min} .\end{array}$ \\
\hline
\end{tabular}

were tested for susceptibility to novobiocin (NV5) also. Cefoxitin (CX30) is used as a surrogate for $m e c A$ mediated methicillin (oxacillin) resistance.

\section{Screening for antibiotic resistance genes}

For Staphylococcal isolates, mecA and mecC (mecA homologue) genes that confer resistance to the $b$ lactam antibiotics were targeted. The oligonucleotide primers, PCR conditions and the corresponding amplicon sizes for the antibiotic resistance genes were mentioned in Table 1. All the Staphylococcal isolates were screened for the presence of mec $A$ gene as per the method of Vishnu priya et al. (2014). The isolates were further subjected to mecC PCR as per the method of Paterson et al. (2012).

\section{RESULTS AND DISCUSSION}

A total of 207 bacterial isolates were obtained from clinical and sub clinical mastitis cases together.
Bacteria isolated were Staphylococcus species (125/207, $60.4 \%$ ) and gram negative bacteria $(82 / 207,39.6 \%)$. Majority of the mastitis cases in this region were due to Staphylococcus $(60.4 \%)$ and gram negative bacteria were the cause of infection only in $39.6 \%$ of the mastitis cases. CoNS account for $64 \%$ (80/125) of the mastitis cases due to Staphylococcus.

\section{Screening for biofilm production ability}

Biofilm formation on Congo red agar was observed in 44.8 per cent $(56 / 125)$ of the Staphylococcal isolates from the present study. The incidence of biofilm phenotype was relatively higher in CoNS isolates $(37 / 80,46.25 \%)$ than CPS $(19 / 45,42.22 \%)$ (Table 2$)$. In contrast to this, Arciola et al. (2001) reported that the incidence of biofilm formation tested with CRA was higher in S. aureus (61\%) than S. epidermidis (49\%) isolates. 
Table 2: Biofilm production ability among the Staphylococcal isolates

\begin{tabular}{llll}
\hline \multirow{2}{*}{ SI. No } & \multirow{2}{*}{ Bacterial species } & \multicolumn{2}{c}{ Bacterial colonies on CRA } \\
\cline { 3 - 4 } & CPS (\%) & Black colonies (biofilm producers) & Red colonies (non-biofilm producers) \\
\hline 1 & CoNS $(\%)$ & $37(42.2)$ & $26(57.8)$ \\
2 & Total & $56(44.8)$ & $43(53.8)$ \\
\hline & & & $69(55.2)$ \\
\hline
\end{tabular}

\section{Detection of biofilm genes by PCR}

Out of the 56 Staphylococcal isolates that were found to form biofilm on Congo red agar only four (7.2\%) were found to possess the bap gene as they showed the amplified product of $971 \mathrm{bp}$ (Fig. 1). The other biofilm genes ica $A, i c a A B$ and aap were not detected in any of these 56 isolates. Although high percentage of the Staphylococcal isolates were phenotypically positive for biofilm production on CRA, biofilm gene (bap) is detected only in four of these isolates.

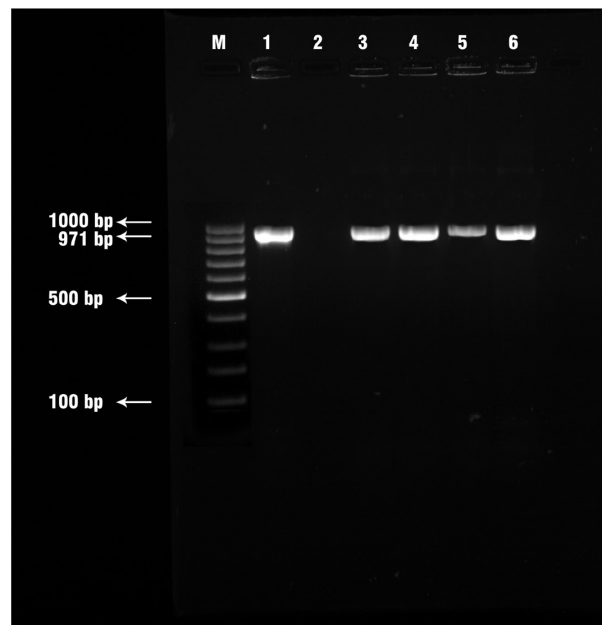

Fig. 1: Duplex PCR for biofilm genes. Lane M: Molecular weight marker (100bp); Lane-1: Reference strain of bap positive S. aureus from previous study as positive control; Lane-2: Negative control; Lane 3-6: Staphylococcal isolates from bovine mastitis showing $971 \mathrm{bp}$ amplicon of bap gene

\section{Phenotypic characterization of antibiotic resistance}

Among the CPS isolates (45), resistance was high to gentamicin $(45,100 \%)$ followed by penicillin $(13$, $28.8 \%)$, cefoxitin $(10,22.2 \%)$ and oxacillin $(4,8.8 \%)$ and all of them were susceptible to ceftriaxone and ciprofloxacin. Among the CoNS isolates (80), resistance was observed to gentamicin (74, 92.5\%), novobiocin (43, 53.8\%), cefoxitin (39, 48.8\%), penicillin $(36,45 \%)$, oxacillin $(35,43.8 \%)$. Most of the CoNS isolates were found susceptible to ceftriaxone and ciprofloxacin (Table 3). Resistance to novobiocin was observed in $53.8 \%(43 / 80)$ of the CoNS isolates. Among 45 CPS and 80 CoNS isolates, 10 CPS and 39 CoNS showed resistance to cefoxitin and hence they were regarded as methicillin resistant (MRSA and MRCoNS) as per CLSI recommendations.

Majority of the CPS and CoNS isolates from our study (around 96\%) were susceptible to ciprofloxacin and ceftriaxone, but most of them were resistant to gentamicin (100\% of CPS and $92.5 \%$ of CoNS). Resistance to cefoxitin was observed to be high among CoNS isolates (48.8\%) when compared to CPS isolates $(22.2 \%)$. Similarly, high percentage of CoNS isolates $(43.8 \%)$ were oxacillin resistant than CPS isolates (9\%). In contrast, Frey et al. (2012) observed low resistance to gentamicin $(2.4 \%)$ and penicillin (23\%) among CoNS isolated from bovine mastitis in Switzerland.

A previous study on bovine mastitis from our laboratory reported high sensitivity of Staphylococcus (CPS and CoNS) to ciprofloxacin, ceftriaxone, gentamicin and 50 per cent resistance to cefoxitin (Usharani, 2016). Contrastingly, Sumathi et al. (2008) observed that gentamicin was the most effective drug against Staphylococci, followed by ciprofloxacin. Chandrasekharan et al. (2014) also observed high sensitivity of Staphylococcal isolates to enrofloxacin followed by gentamicin and ceftriaxone. Development of resistance against a particular antibiotic in a specific region might be due to frequent and long term use and under dosage (Sabour et al., 2004, Moon et al., 2007 and Kumar et al., 2010). 
Table 3: Antibiotic susceptibility of CPS and CoNS isolates

\begin{tabular}{lllllll}
\hline \multirow{2}{*}{ Antibiotic } & \multicolumn{9}{c}{ CPS } \\
\cline { 2 - 6 } & Resistant (\%) & Intermediate (\%) & Susceptible (\%) & Resistant (\%) & Intermediate (\%) & Susceptible (\%) \\
\hline CX-30 & $10(22.2)$ & - & $35(77.8)$ & $39(48.8)$ & - & $41(51.3)$ \\
P-10 & $13(28.9)$ & - & $32(71.1)$ & $36(45)$ & - & $44(55)$ \\
GEN-10 & $45(100)$ & - & - & $74(92.5)$ & - & $6(7.5)$ \\
CIP-5 & - & $1(2.2)$ & $44(97.8)$ & $2(2.5)$ & $1(1.3)$ & $77(96.3)$ \\
CTR-30 & - & $2(4.4)$ & $43(95.6)$ & $3(3.8)$ & $13(16.3)$ & $64(80)$ \\
OX-1 & $4(8.9)$ & - & $41(91.1)$ & $35(43.8)$ & - & $45(56.3)$ \\
NV-5 & - & - & - & $43(53.8)$ & - & $37(46.3)$ \\
\hline
\end{tabular}

\section{Screening for antibiotic resistance genes}

In PCR for mec $A$ and mecC genes, only eight isolates $(8 / 125,6.4 \%)$ of Staphylococci were found to possess mecA gene with amplicons of $310 \mathrm{bp}$ (Fig. 2) and they were confirmed as methicillin resistant. Out of these $8 \mathrm{mec} A$ positive isolates, 3 were methicillin resistant $S$. aureus and the remaining 5 were methicillin resistant CoNS isolates. Out of these 8 isolates, 3 were coagulase positive and 5 were coagulase negative and in none of the isolates, the expected amplicon product of $188 \mathrm{bp}$ was found and hence it is considered that they were all not carrying mecC gene.

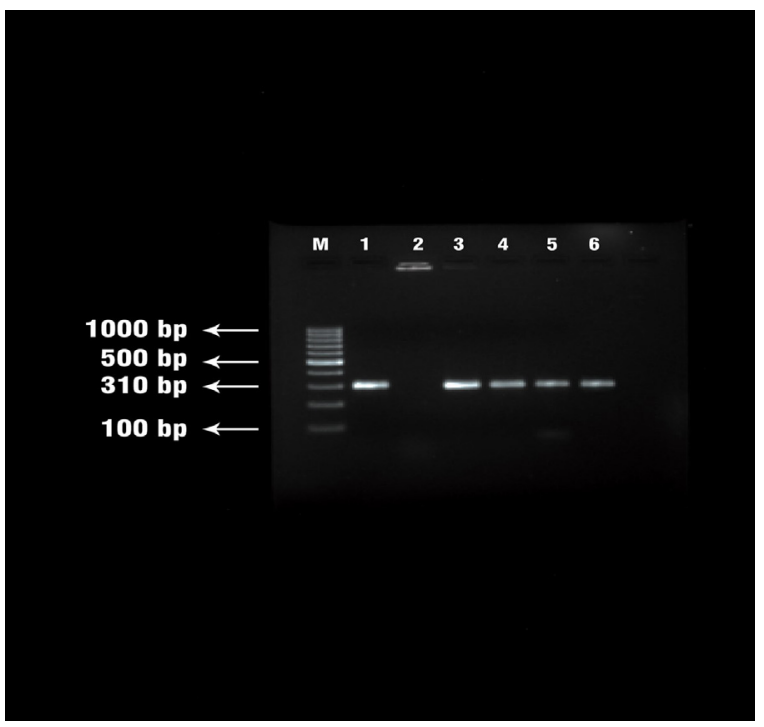

Fig. 2: PCR for mecA gene. Lane M: Molecular weight marker (100bp); Lane-1: Reference strain of mecA positive $S$. aureus from previous study as positive control; Lane-2: Negative control; Lane 3-6: Staphylococcal isolates from bovine mastitis showing $310 \mathrm{bp}$ amplicon of $m e c A$ gene
Out of the 49 Staphylococcal isolates that were phenotypically identified as positive for mecA mediated oxacillin resistance in the cefoxitin disc test, $m e c A$ gene was detected only in 6 isolates and other 2 isolates that were found to carry mecA gene were phenotypically susceptible to cefoxitin. None of the Staphylococcal isolates were positive for mecC gene indicating no prevalence of methicillin resistance by harboring mecC gene. All the eight mecA positive isolates were resistant to gentamicin and only six of them were resistant to cefoxitin and 5 to penicillin. But only 2 isolates were resistant to oxacillin, the other 6 mec A positive isolates (3 CPS, 3 CoNS) were found susceptible to oxacillin ( $1 \mathrm{mcg}$ ) disc.

In a similar study, Piessens et al. (2012) reported low incidence of mec $A$ gene (11.7\%) from 366 CoNS isolated from milk. Srednik et al. (2017) also reported low incidence of mecA gene (4) compared to blaZ gene (21) among CoNS (87) isolates from bovine mastitis. Srednik et al. (2015) also reported low incidence of mecA gene (6) when compared to blaZ gene (19) in CoNS (93) isolates from bovine mastitis.

According to the results of the present study, the prevalence of methicillin resistant phenotype was considerably high among CoNS (39/80, 49\%) though only 6.25 per cent (5/80) of them carried mecA gene and could be confirmed as MRCoNS. As indiscriminate use of antibiotics was one of the reasons for development of resistance, there is necessity for the implementation of in vitro antibiotic susceptibility test prior to the use of antibiotics in the treatment and prevention of intra mammary 
infections. Further investigation to establish the molecular basis of antibiotic resistance and biofilm potential is required.

\section{CONCLUSION}

The occurrence of biofilm producing and methicillin resistant phenotype is considerably high among the Staphylococci from bovine mastitis but, the mecA gene is detected only in $6.4 \%$ of them. Biofilm gene 'bap' is detected in only $7.2 \%$ of the biofilm forming isolates.

\section{ACKNOWLEDGEMENTS}

The authors are thankful to the Sri Venkateswara Veterinary University for supporting the study.

\section{REFERENCES}

Arciola, C.R., Baldassarri, L. and Montanaro, L. 2001. Presence of icaA and icaD genes and slime production in a collection of Staphylococcal Strains from catheter-associated infections. $J$. Clin. Microbiol., 39(6): 2151-2156.

Chandrasekaran, D., Venkatesan, P., Tirumurugaan, K.G., Nambi, A.P., Thirunavukkarasu, P.S., Kumanan, K. and Ramesh, S. 2014. Pattern of antibiotic resistant mastitis in dairy cows. Vet. World, 7: 389-394.

Clinical and Laboratory Standards Institute. 2014. Performance Standards for Antimicrobial Susceptibility Testing; Fifteenth Informational Supplement, M100-S24, Wayne, PA, USA.

Frey, Y., Rodriguez, J.P., Thomann, A., Schwendener, S. and Perreten, V. 2012. Genetic characterization of antimicrobial resistance in coagulase-negative Staphylococci from bovine mastitis milk. J. Dairy Sci., 96: 2247-2257.

Iorio, N.L.P., Azevedo, M.B., Frazao, V.H., Barcellos, A.G., Barros, E.M., Pereira, E.M., Mattos, C.S. and Santos, K.R.N. 2011. Methicilllin-resistant Staphylococcus epidermidis carrying biofilm formation genes: detection of clinical isolates by multiplex PCR. Int. Microbiol., 14: 13-17.

Janeczko, K.P., Lis, P., Bierowiec, K., Rypula, K. and Chorbinski, P. 2014. Identification of bap and icaA genes involved in biofilm formation in coagulase negative Staphylococci isolated from feline conjunctiva. Vet. Res. Commun., 38: 337346.

Kumar, A., Rahal, A., Dwivedi, S.K. and Gupta, M.K. 2010. Bacterial prevalence and antibiotic resistance profile from bovine mastitis in Mathura, India. Egypt. J. Dairy Sci., 38(1): $31-34$
Mariana, N.S., Salman, S.A., Neela, V. and Zamberi, S. 2009. Evaluation of modified Congo red agar for detection of biofilm produced by clinical isolates of methicillin-resistance Staphylococcus aureus. Afr. J. Microbiol. Res., 3(6): 330-338.

Moon, J.S., Lee, A.R., Kang, H.M., Lee, E.S., Kim, M.N., Paik, Y.H. and Koo, H.C. 2007. Phenotypic and genetic antibiogram of methicillin-resistant Staphylococci isolated from bovine mastitis in Korea. J. Dairy Sci., 90(3): 1176-1185.

Paterson, G.K., Larsen, A.R., Robb, A., Edwards, G.E., Pennycott, T.W., Foster, G., Mot, D., Hermans, K., Baert, K., Peacock, S.J., Parkhill, J., Zadoks, R.N. and Holmes, M.A. 2012. The newly described mecA homologue, mecALGA251, is present in methicillin-resistant Staphylococcus aureus isolates from a diverse range of host species. J. Antimicrob. Chemother, 67: 2809-2813.

Piessens, V., Vliegher, S.D., Verbist, B., Braem, G., Nuffel, A.V., Vuyst, L., Heyndrickx, M. and Coillie, E.V. 2012. Characterization of coagulase negative Staphylococcus species from cow milk and environment based on bap, $i c a A$ and mecA genes and phenotypic susceptibility to antimicrobials and teat dips. J. Dairy Sci., 95(12): 7027-7038.

Sabour, P.M., Gill, J.J., Lepp, D., Pacan, J.C., Ahmed, R., Dingwell, R. and Leslie, K. 2004. Molecular typing and distribution of Staphylococcus aureus isolates in Eastern Canadian dairy herds. J. clin. microbiol., 42(8): 3449-3455.

Srednik, M.E., Grieben, M.A., Bentancor, A. and Gentilini, E.R. 2015. Molecular identification of coagulase negative Staphylococci isolated from bovine mastitis and detection of ß-lactam resistance. J. Infect. Dev. Ctries., 9(9): 1022-1027.

Srednik, M.E., Tremblay, Y.D.N., Labrie, J., Archambault, M., Jacques, M., Cirelli, A.F. and Gentilini, E.R. 2017. Biofilm formation and antimicrobial resistance genes of coagulase negative Staphylococci isolated from cows with mastitis in Argentina. FEMS Microbiol., 364(8): 1-8.

Sumathi, B.R., Veeregowda, B.M. and Amitha, R.G. 2008 Prevalence and antibiogram profile of bacterial isolates from clinical bovine mastitis. Vet. World, 1(8): 237-238.

Tremblay, Y.D.N., Lamarche, D., Chever, P., Haine, D., Messier, S. and Jacques, M. 2013. Characterization of the ability of coagulase negative Staphylococci isolated from the milk of Canadian farms to form biofilms. J. Dairy Sci., 96(1): 234246.

Usharani, K. 2016. Studies on antibiotic resistance among major bovine mastitis pathogens in Andhra Pradesh. MVSC. thesis submitted to Sri Venkateswara Veterinary University, Tirupati.

Vishnu Priya, S., Antony, P.X., Mukhopadhyay, H.K., Pillai, R.M., Thanislass, J., Srinivas, V.M.V. and Kumar, R.S. 2014 Methicillin resistant Staphylococci associated with bovine mastitis and their zoonotic importance. Vet. World, 7(6): 422427. 